\title{
Análise do desenvolvimento das práticas urbanas de lazer relacionadas a produção cultural no período nacional-desenvolvimentista à globalização
}

CDD. 20.ed. 790.1

796.08
Marco Antonio Bettine de ALMEIDA* Gustavo Luis GUTIERREZ**

\section{Resumo}

Apresentar-se-á um cenário geral do desenvolvimento do lazer desde o nacional-desenvolvimentismo com Getúlio Vargas, Juscelino Kubitschek, Regime Militar até a globalização com a redemocratização e ampliação vertiginosa do lazer de consumo. Este panorama geral possibilitará afirmar que o lazer se desenvolveu pelo investimento estatal. Discutiu-se cada um dos momentos históricos contemplando as ações políticas, econômicas e culturais mais significativas, conforme análise bibliográfica. Objetivou-se construir neste trabalho a complexificação sistêmica do lazer no Brasil, concluindo que o lazer se complexificou a partir da racionalização das formas de vida, sistematização dos tempos e desencantamento do mundo. Com a teoria habermasiana fez-se a sintese entre as esferas de influência do lazer (Estado, Mercado e Cultura). $\mathrm{Na}$ conclusão apresentou-se a definição do lazer como fruto das relações entre subjetividades intactas no sistema capitalista, que se desenvolveu por meio da complexificação da sociedade, possuindo uma íntima ligação cultural-artística. Expressando as três esferas do Mundo da Vida (cultura, sociedade e personalidade).

UnIteRMos: Lazer; Cultura; História.

\section{Introdução}

O trabalho discutirá as práticas de lazer e seu desenvolvimento no período que vai do nacionaldesenvolvimentista até a globalização, abordando a produção artística do período, as políticas públicas e a inserção do setor privado, tendo como parâmetro de análise a teoria habermasiana da ação comunicativa, que entende a sociedade pela sua divisão em Mundo da Vida e Sistemas, por meio do processo denominado por Habermas de complexificação sistêmica da sociedade.

O estudo terá como ponto de partida o Estado Novo, onde houve o crescimento da urbanização, o desenvolvimento industrial e o florescimento de uma produção cultural nacional. A opção se deu pela percepção de que a urbanização é um dos elementos chave para compreender o lazer.

O lazer tem um amplo desenvolvimento na urbanização, absorvendo elementos da cultura, das artes e das relaçôes sociais. Com a evolução das relações sociais, econômicas, artísticas, políticas, culturais há a complexificação do lazer, formando um corpo que se inter-relaciona com as outras esferas da sociedade.

Na primeira parte do artigo apresentar-se-á a discussão metodológica, levantando algumas categorias habermasianas como Sistema e Mundo da Vida, colocando como Habermas interpreta a sociedade e desenvolve o conceito de colonização do Mundo da Vida e Complexificação Sistêmica, conceitos que somados às duas categorias são de fundamental relevância para compreender os caminhos do lazer no Brasil. Com as categorias fundamentais expostas e a compreensão do desenvolvimento do lazer via teoria habermasiana.

A segunda parte propóe-se compreender as práticas de lazer no período nacional-desenvolvimentista. Primeiramente apontando as transformações sociais, políticas e econômicas no Estado Novo e suas influências na estruturação do lazer e abordando, também, a produção cultural e a participação das políticas públicas estatais no tempo livre da população. Posteriormente será discutida a 
influência estadonovista para a consolidação do teatro, rádio, cinema e cultura popular. Outro momento importante do nacional-desenvolvimentismo foi o governo de Juscelino Kubitschek, nele aparecerão as primeiras formas de lazer cosmopolitas e de tendências nacionalistas de esquerda, principalmente com o movimento nacional-popular e da contra-cultura.

$\mathrm{Na}$ terceira parte discutir-se-á o lazer na ditadura militar destacando os avanços (indú

stria cultural) e retrocessos (censura) de suas práticas. Na primeira parte deste item apresentarse-á a instauração, o recrudescimento e a mobilização política no regime, bem como o sucesso do milagre econômico, o insucesso da luta armada e a lenta abertura política. Posteriormente, a censura e a repressão da produção cultural serão analisadas, mostrando como houve refluxo cultural no período. Para finalizar, construir-se-á a tese sobre a gestação da industria cultural no caso brasileiro.

Será estudado na última parte a redemocratização e a globalização como faces do lazer brasileiro. A primeira pela tentativa de retornar ao nacional-popular "perdido" na época anterior, e o segundo pela consolidação da mundialização nas práticas de lazer. A categoria globalização será discutida por diversos autores, incluso Habermas que defende a ideia de desenvolvimento da esfera pública. Com estes pressupostos discutir-se-ão as atividades de lazer na globalização.

\section{Teoria habermasiana e método de pesquisa}

\section{Sistema e mundo da vida: duas categorias habermasianas}

Pela perspectiva habermasiana a sociedade é constituída por duas realidades, o Mundo a Vida e o Sistema.

O Mundo da Vida se expressa quando os sujeitos criam os contextos sociais para viver em grupo, produzindo objetos simbólicos que corporificam estruturas normativas, subjetivas, objetivas e associativas, fundamentais para a consolidação da vida em sociedade.

O conceito, Mundo da Vida, habermasiano, não se atém somente a um ponto de vista cultural, este é insuficiente para a "Teoria da Ação Comunicativa", uma vez que o Mundo da Vida não se restringe a um mero processo de produção simbólica. Porque alcançando isso se deve consolidar o entendimento sobre algo no mundo, por meio dos quais as pessoas desenvolvem, confirmam e renovam suas pertenças a grupos sociais, as formas de vida e as suas identidades. O conceito de mundo da vida corresponde a três estruturas formadoras essenciais: cultura, personalidade e sociedade - que são seus componentes invariantes e atemporais. Portanto, o mundo da vida corresponde a uma forma de cultura, um tipo de sociedade e uma estrutura de personalidadevariável temporal e historicamente, tendo na linguagem o meio de constituição destas estruturas.

Para Habermas (1987a, 1987b) a linguagem seria o verdadeiro traço distintivo do ser humano, pois lhe atribui a capacidade de tornar-se um ser: individual, social e cultural. Fornecendo-lhe uma identidade e possibilitandothe partilhar estruturas de consciência coletiva.

O Sistema, por sua vez, é formulado pela perspectiva de ganhos sobre o outro, a partir da colonização do
Mundo da Vida e incorporação da linguagem voltada para o uso instrumental. A razão instrumental representa esse modo de conhecer do sujeito que se apropria dos objetos de conhecimento unicamente com a finalidade de dominá-los e utilizar-se deles para fins egocêntricos.

O Sistema surgirá somente com o desenvolvimento da sociedade, por meio da complexificação sistêmica, quando os mecanismos sistêmicos se apóiam nas estruturas do Mundo da Vida colonizando-os para uso estratégico.

Apoiado nas análises weberianas, Habermas vai explicar que, em virtude da aquisição de um novo estágio de estruturas de consciência moral e legal, as esferas de valores culturais, sociais e subjetivas criam autonomia, adquirem lógicas próprias e se institucionalizam em sistemas. Esta racionalização cultural permite um aumento do nível de complexidade sistêmica, exemplificada pela institucionalização da economia capitalista e do Estado moderno. Neste momento histórico ocorre a diferenciação dos sistemas de ação econômico e administrativo, o Sistema separase em Sistema Poder e Sistema Dinheiro, a dinâmica de independência desses sistemas sociais em torno de dinheiro e poder é tão forte que eles se tornam totalmente desligados dos valores culturais. Dar-se-ia, assim, a cisão, a ruptura entre Sistema e Mundo da Vida, ocorrendo o estágio atual da sociedade moderna.

Mesmo com os avanços da política, economia, urbanização, trabalho, Habermas afirma que existe apenas uma realidade primordial, o Mundo da Vida, essencialmente comunicativo, que deve ser vivenciado, pois é nele que as pessoas vivem pensam e se relacionam. 
Segundo Habermas (1987b) o mundo da vida atualmente é o espaço de construção da linguagem por meio da cultura, cuja função é conservar os costumes e as normas de ação socialmente válidas; a personalidade, responsável pela socialização e manutenção de valores morais; e a sociedade, que tem por objetivo constituir as formas de integração entre sujeitos.

Com o desenvolvimento dos Sistemas sobre o Mundo da Vida ocorrem patologias sociais, ficando mais nítidas no capitalismo, como a perda de alguns valores morais, dos sentido das tradições, da anomia e dos distúrbios de formação da identidade. Tornando a sociedade presa a tradições sem conteúdo normativo, extremamente individualista e perdendo cada vez mais a relação intersubjetiva.

Habermas não propõe uma solução para patologias, mas poder-se-á apontar, como possível saída, a restituição da moralidade perdida, o revigoramento do poder integrador da sociedade, a reconquista do espaço público e o fortalecimento da sociedade civil enquanto órgão de discussão para a coordenação da açãao social. Para que isso possa acontecer torna-se necessário restaurar o equilíbrio entre a lógica e a dinâmica do desenvolvimento, fazer com que a lógica sistêmica passe a ser controlada pela lógica interativa, de tal forma que impeça o predomínio dos meios não integradores sobre o meio comunicativo.

\section{Olazervia "Teoria daAção Comunicativa"}

O lazer interpretado via "Teoria da Ação Comunicativa" seria essencialmente uma relação social que se expressa no Mundo da Vida. A essência da produção cultural ligada ao lazer é ser mais um interlocutor do Mundo da Vida, servindo para a evolução da linguagem, das instituições e formação da personalidade, portanto o lazer expressaria os três mundos: social (relação entre as pessoas); objetivo (transformação da natureza) e pessoal (construção da subjetividade).

Pode-se afirmar que o lazer surge no mundo da vida por meio da integração entre as pessoas, da busca do divertimento e da vontade de sentir prazer. A complexificação do lazer dá-se nas sociedades modernas com: a) sistematização dos tempos (separação do mundo das obrigações e do divertimento); e b) desencantamento do mundo (racionalização das formas de vida).

A análise aqui proposta vincula três tendências do lazer, a primeira tendência é a que vê o lazer pelos olhos da cultura - como componente do mundo da vida o lazer tem uma dimensão cultural importante; a segunda tendência que discute o papel do Estado como grande propulsor do lazer - o lazer também existe de forma colonizada no sistema poder; e a última tendência que defende a função do Mercado como prioritário para o lazer - o sistema dinheiro também colonizou alguns elementos do lazer e incorporou como mercadoria. A teoria habermasiana avança frente a outras interpretaçóes porque a Teoria da Ação Comunicativa sintetiza várias esferas de influência do lazer (Cultura, Estado e Mercado), colocando a interação entre elas como a forma que o lazer na sociedade contemporânea se expressa.

Portanto, o lazer expressa as três esferas do Mundo da Vida (cultura, sociedade e personalidade), estas esferas estão em simbiose que podem ser exemplificadas pela: livre vontade do indivíduo em fazer a atividade; prazer que está buscando; espaço social que ocorre a atividade; trocas com outros sujeitos; e ação ser considerada pelo agrupamento como sendo lazer, de acordo com os costumes do lugar. Será lazer se o indivíduo esteja se relacionando com seus pares (cultura), buscando prazer (personalidade) e se aquela atividade é considerada lazer pelo grupo (sociedade).

Nas sociedades complexas o lazer se desloca do Mundo da Vida sendo apropriado pelo Sistema, se expressando através das ações políticas do Estado como o Esporte para Todos no regime militar; das ações do Mercado como a industria cultural; e logicamente, nas relações espontâneas no mundo da vida como o folclore.

\section{As práticas de lazer no período nacional-desenvolvimentista}

\section{Transformações do Estado Novo e suas influências na estruturação do lazer}

No Brasil o fenômeno "populismo" tem na figura de Getúlio Dornelles Vargas o seu maior representante. SANTOS (2004) coloca que populismo era a união do carisma com a estruturação de um aparato midiático. Particularmente, o presidente Getúlio Vargas desenvolveu toda uma estrutura ideológica política, através do Departamento de Imprensa e Propaganda (DIP) e do Cine-Jornal (curtas metragens que abordavam as obras e feitos do presidente), para sustentar e construir sua figura de grande estadista. Segundo Capelato (1999, 
p.169) as comemoraçôes relativas ao dia do trabalho, à semana da pátria, aos aniversários do presidente e à instauração do Estado Novo foram momentos importantes no lazer do trabalhador que foram utilizados para construir a imagem do presidente.

O Cine-Jornal, particularmente, foi o veículo comunicativo mais importante do Estado Novo (SANTOS, 2004, p.40-5), porque atingia a classe urbana e registrava as açôes do governo. Foi a primeira grande forma de propaganda política audiovisual.

É interessante notar que as festas, propagandas, comícios, paradas que ocorriam no momento de lazer do trabalhador, possuíam dupla função: a primeira de construção da imagem do presidente e a segunda como atividades para afastar a ociosidade dos operários. Quanto a esta segunda função não é demais lembrar que o Código Penal brasileiro de 1941 tratava de forma especial o crime contra a moral e os bons costumes, com o título de "vagabundagem". As açóes do governo objetivavam a ordem por meio de atividades que mantivessem ativos os trabalhadores para não se envolverem com qualquer tipo de ação ilícita. Vargas foi o primeiro presidente que utilizou o tempo livre como propaganda e controle.

Parte deste controle, contra os elementos nocivos e a ociosidade dos trabalhadores, foi materializado a partir da proibição de jogos e ritos populares, como a briga de galo, a briga de canários, as fogueiras de São João e restrições às festas carnavalescas. Já nos primeiros anos da década de 30, o governo Vargas por meio do Departamento de Turismo, proibiu e controlou as manifestaçóes populares carnavalescas, principalmente pela violência e número de vítimas. $\mathrm{O}$ mesmo movimento ocorreu com as escolas de samba, um decreto-lei de 1937 determinou que as escolas de samba dessem um caráter didático (histórico e patriótico) aos sambas-enredos.

A ideia de racionalização das atividades de tempo livre, principalmente das camadas populares, foi uma das formas de manifestar o controle e de inserir na mente da nação os valores mais altos de civilidade projetados pelo governo de Vargas.

O Estado Novo foi um período muito fértil no que se refere à produção cultural, fatos que confirmam esta afirmativa, segundo SANTOS (2004, p.18-21), são o vertiginoso aumento de livros, revistas, folhetos, cartazes, programas de rádio com noticiários e números musicais, além do surgimento da rádio-novela, cine-jornal e documentários cinematográficos. Estas atividades que tratam diretamente do tempo de não trabalho tiveram um papel ativo na formação do lazer do trabalhador, que conquistaria neste mesmo período a CLT e poderia desfrutar de novas práticas de lazer, como ouvir música, assistir filme e ir ao teatro.

SKIDMORE (1975) coloca que apesar de ter o nacionalismo como um dos seus pilares de sustentação, paradoxalmente foi durante o Estado Novo que o Brasil entrou definitivamente na órbita cultural dos Estados Unidos. Nessa ocasião o personagem de quadrinhos Zé Carioca fora criado pelos Estúdios Disney e Carmem Miranda foi erigida ícone da boa vizinhança entre os Estados Unidos e o Brasil.

Neste momento de transformações sociais o próprio momento de lazer era utilizado estrategicamente para o exercício de poder. Este fato, segundo ARENDT (1989), é típico dos regimes totalitários. O governo forte e centralizador detêm os meios de comunicação exercendo uma censura rigorosa sobre as informações, e, ao fazêlo, mantém para si a divulgação dos temas relevantes para a manutenção do próprio sistema. O tempo livre, por sua vez, serviria para promover encontros e festas, materializando a própria propaganda do governo.

O meio comunicativo para esta ação foi o rádio, por dois motivos: o primeiro que era um canal informativo importante das classes urbanas e o segundo pelo seu poder de alcance. $\mathrm{O}$ rádio passou a fornecer informaçōes oficiais à imprensa e também a produzir e editar o programa "A Hora do Brasil". Foi justamente no Estado Novo que o rádio passou de um público elitizado desde sua inauguração em 1922 com programação de concertos, recitais e palestras -, para um público mais amplo. $\mathrm{O}$ fator mais importante deste acontecimento foi o investimento estatal na aquisição de receptores, anteriormente importados. Segundo AvanCINI (1996) o rádio, antes do governo Vargas, tinha uma finalidade cultural, educativa e altruísta elitista - cabe lembrar que os anúncios pagos eram proibidos. Somente no Estado Novo o governo autorizou os comerciais nos rádios, ocorrendo uma profissionalização das emissoras com artistas e produtores.

Foi durante o período do Estado Novo que o rádio tornou-se o principal meio de comunicação brasileiro, momento denominado época de "Ouro do Rádio" (Avancini, 1996). O impacto do rádio sobre a sociedade brasileira nesta época foi muito profundo, com uma grande abrangência, público e aproximação da população. A sua grande revolução deu-se com a produção da rádio-novela.

\section{O teatro, o rádio, o cinema e a cultura popular sob influência estadonovista}

Grandes companhias de teatro foram criadas nas décadas de 30 e 40, participando do movimento 
de construção da arte brasileira e consolidação da cultura urbana. Jaime Costa, Procópio Ferreira, Abigail Maia e Dulcina de Moraes fundam suas companhias, ativas até o fim dos anos 50, construindo espaços que se inserem na própria revolução urbana iniciada no Estado Novo. OTBC (Teatro Brasileiro de Comédia), marco na história do teatro brasileiro, também foi deste período, sendo uma referência nas atividades de lazer para um público intelectualizado.

O cinema, como cultura tipicamente urbana, se consolida neste período. Primeiramente com o Estado investindo nos equipamentos e tecnologia, e também, promulgando leis que incentivassem a produção nacional, como o decreto lei de 1932, que obrigava a exibição de filmes nacionais.

O grande investimento do Estado na aérea cinematográfica foi o Cine-jornal, voltado para a propaganda governista, a ideia nacionalista e do homem novo. O cine-jornal focava exposições e concursos artísticos, cenas do Carnaval carioca, desfiles de moda, diversas modalidades de esportes (esgrima, o turfe, a natação, as provas de automobilismo, o hipismo, o remo e o futebol), as romarias e festas populares, aniversário de pessoas vivas ou mortas, instituiçōes, datas cívicas ou militares.

O cinema das grandes companhias se desenvolveu no começo da década de 30 com a instalação do primeiro estúdio cinematográfico do país, a Cinédia, posteriormente, foram criados a Atlântida e a Vera Cruz (CATANi, 2002). A Cinédia produziu dramas populares e comédias musicais que ficaram conhecidas pela denominação genérica de chanchadas (GALVÃo, 1983). A Atlântida, fundada em 1941 por Moacir Fenelon, Alinor Azevedo e José Carlos Burle, estreia com "Moleque Tião", filme que procura ilustrar o nacionalismo e temas regionais. Este gênero domina o mercado até meados de 1950, promovendo comediantes como Oscarito, ZéTrindade, Grande Otelo e Dercy Gonçalves.

O cinema e o teatro, aos poucos, ganharam espaço para consumo do público. Com o avanço tecnológico e desenvolvimento urbano as grandes cidades começam a construir locais próprios para as apresentaçōes, impulsionando, ainda mais, o mercado nacional. Segundo a bibliografia consultada (Bernardet, 1985; Catani, 2002; Santos, 2004) há uma relação entre o desenvolvimento urbanotecnológico e a ampliação das atividades de lazer.

Durante o grande avanço urbano-industrial o rádio se popularizou; surgiram grandes companhias cinematográficas; as atividades folclóricas foram racionalizadas em apresentaçôes teatrais; surgiram companhias de teatro e uma dramaturgia de renome; a criação de um departamento governamental para gerir a produção artística e as atividades de lazer. Durante todo o período getulista ocorreu grande desenvolvimento artístico, no lazer e nas atividades urbanas do tempo livre.

\section{O lazer no fim da era Vargas e no governo de J uscelino Kubitschek}

No período posterior a Vargas houve uma ampliação das atividades de lazer, devido ao crescimento do desenvolvimento industrial, da urbanização e do acesso aos bens culturais estrangeiros.

A década de 50 e, particularmente, o governo JK, constituem-se um período muito rico de nossa história. Viveu-se um momento significativo de mudanças em praticamente todos os aspectos: social, econômico, político e cultural (SKIDMORE, 1975). Este contexto de profunda inquietação social, por um lado gerava um receio político; mas, por outro era fonte de inspiração de peças teatrais, de musicais e de filmes. A ênfase no desenvolvimento econômico e industrial impulsionou transformaçôes que possibilitaram um maior acesso ao lazer, por meio do desenvolvimento das artes e espetáculos. Foi o momento de valorização do lazer do trabalhador com a construção dos clubes operários, principalmente com a chegada de empresas estrangeiras que já estruturavam em suas sedes as atividades operárias, construindo espaços de lazer para seus funcionários.

Somente em 1960, segundo dados do IBGE (Instituto Brasileiro de Geografia Estatística), a população urbana ultrapassa a rural. Esse dado reforça a ideia de que durante toda a Era Vargas e grande parte de JK vamos encontrar um conflito entre o lazer rural (práticas populares, folclore, jogos, comemoraçōes) e o urbano (teatro, cinema, passeios, viagens). Como salienta CorBIN (1995, p.56), o lazer em França firmase na sociedade industrial por meio das conquistas trabalhistas, como a diminuição da jornada de trabalho, aumento dos espaços de lazer nas empresas, participação dos operários nos campeonatos nacionais e desenvolvimento esportivo de alguns clubes operários. Com a população urbana superando a rural ocorre o mesmo fenômeno no Brasil, os operários exigem tempo livre e atividades de lazer, revolucionando o lazer nas cidades industrializadas e consolidando o lazer moderno nas regiōes sul e sudeste.

A partir destas constatações fica mais claro abordar o lazer na Era Vargas e seu desenvolvimento no período de JK. Com a ampliação da população das grandes cidades, a migração e a transformação do espírito camponês para o espírito industrial ocorreu um envolvimento 
das pessoas com as atividades lúdicas delimitadas em um tempo. A disposição delas para tal fenômeno levou a uma ampliação da produção artística, construindo espaços tanto em bairros operários como de classe média. Nos bairros já havia o cinema que passava o cinejornal, ampliando-o para atividades teatrais, artísticas, ou mesmo para grupos operários - que cresce com a influência dos sindicatos (CosTA, 1995).

Frente a uma classe urbana crescente, onde se destaca uma massa de estudantes que super-povoa as universidades públicas das grandes metrópoles, desenvolve-se de forma acelerada a prática de esporte nos clubes, a importância da casa de campo ou praia e os passeios de carro pela rede de estradas em expansão. Os passeios de fim-de-semana cresceram com a ascensão da classe média, ao mesmo tempo em que as Prefeituras e Estados investem em parques e espaços para práticas esportivas. Como exemplo deste fato, em 1951 o parque Ibirapuera de São Paulo é inaugurado, com uma concepção arquitetônica peculiar do arquiteto Oscar Niemeyer, tornando-se referência de lazer, cultura, arte e música para os paulistanos.

Com o surgimento de novos espaços para a produção artística ocorre uma ampliação dos espetáculos no período desenvolvimentista. Frente a um público em ampla expansão surgiram companhias de teatro, cinematográficas e circenses que procuravam pensar e incorporar, por meio das apresentações, as características do povo brasileiro. A busca de uma identidade nacional estava na música com a Bossa Nova, a Tropicália, o Cinema Novo e o Teatro de Arena.

A perseguição constante de um enigmático "homem brasileiro", a ânsia em apreender a "realidade brasileira” perpassa pelas várias expressōes artísticas como apontado por Hollanda (1980) e RidENTI (1999). Trata-se da intrincada questão da identidade nacional que atormentou o mundo artístico nacional.

Com o crescimento da importância do lazer e sua inserção no desenvolvimentismo brasileiro, ocorre o processo de diferenciação econômica pelo lazer. Por um lado, o encanto de rico país tropical que associava a festa e o carnaval com os prédios, as estradas e as indústrias, fora um produto de consumo para classes altas. Por outro lado, o lazer popular mantinha a tradição do lazer de rua, o circo e as festas típicas católicas. As práticas esportivas, particularmente, tinham como espaço a rua, a empresa e os campos improvisados. $\mathrm{Na}$ cidade, ainda em desenvolvimento, havia espaço livre para a população de baixa renda organizar atividades lúdicas, enquanto que os setores mais abastados tinham os clubes esportivos e os parques públicos situados, em geral, nas regiōes mais valorizadas.
Como há a diferenciação destes dois tipos de lazer, o primeiro ligado a uma classe alta e média e, o segundo aos operários, ocorre a formação de lazeres brasileiros. $\mathrm{O}$ do primeiro grupo se vincula diretamente a urbanização, com inúmeras atividades e opçóes que acompanham o avanço tecnológico e a industrialização. $\mathrm{O}$ segundo têm um processo de desenvolvimento tardio, pois as zonas mais afastadas do centro urbano não se desenvolveram à velocidade dos centros financeiros e comerciais, por isso, o lazer mantém-se próximo às estruturas rurais, ou um sistema híbrido de rural na cidade.

A televisão também reproduziu a tônica deste período de urbanização e desenvolvimento tecnológico. Estudos de Kornis (1994, p.45) mostram a televisão como nova expressão artística, trazida em 1950 por Assis Chateaubriand. Segundo pesquisa da autora a TV Tupi-Difusora de São Paulo foi a primeira emissora de televisão da América Latina. O programa "TV de Vanguarda” revelou a primeira geração de atores, atrizes e diretores. Alguns programas dos primeiros tempos da TV Tupi tornaram-se campeões de audiência e permanência no ar, como: "Alô Doçura" e "Sítio do Pica-pau Amarelo".

O lazer ancorado na urbanização e tecnologia não foi consenso, houve grupos e movimentos artísticos que influenciaram o consumo do lazer absorvendo os elementos nacionais numa espécie de contra-cultura. Estes grupos não tinham como meta a busca do "homem brasileiro" da era Vargas, como também, não queriam uma arte cosmopolita incorporada ao estrangeirismo. Estes grupos formaram o movimento do nacional-popular, tendo nas práticas de lazer, como: teatro, cinema, música e literatura suas formas de expressão. Neste próximo item discutir-se-ão estes movimentos marginalizados em Kubitschek que ganham força com a renúncia de Jânio Quadros e o plebiscito de João Goulart, perdendo espaço com o golpe militar de 1964.

\section{Osurgimento do nacional-popularno lazer}

A adoção da arte popular e da temática brasileira pela contra-cultura nas atividades de tempo livre, como teatro, cinema e rádio, se justificavam pela preservação dos valores nacionais ameaçados pela invasão cultural norte-americana. Em consequência disso, a arte nacional popular opta por uma espécie de relação com o povo, levando até os limites da interferência estética para aproximação da população.

FAVARETTO (2000) afirma que o movimento de contra-cultura era múltiplo, não existindo um único projeto, havia vários grupos paralelos que tinham na 
brasilidade seu foco de ação, por exemplo: o CPC (Centro Popular de Cultura), Cinema Novo (tendência do cinema tendo Glauber Rocha como maior expoente), Arena (grupo de teatro) e obras literárias. Na sua maioria os artistas não tinham uma educação política partidária que daria sustentação para a mudança do sistema capitalista: o Cinema Novo, os Tropicalistas e o grupo Arena são exemplos de uma revolução estética, enquanto o CPC representa a arte engajada. A busca do nacional-popular era mais importante para um grupo, enquanto, a arte engajada era prioridade para outro. Esta passagem leva-nos a entender que o período do pré-64 não era esquerdistacomunista. Na realidade foi um período de agitação político-cultural, que tinha várias tendências, desde a expressão da arte dominante até a contra-cultura.

Para OrTiz (1988), a televisão, ainda incipiente enquanto projeto da indústria cultural, tinha como objetivo este nacional-popular, exemplo disso foi a criação da TV Excelsior, pertencente ao grupo Simonsen, fortemente nacionalista, fundada em 1960. Para se ter ideia a TV Excelsior apoiou o General Lott (PTB) - fortemente nacionalista - na eleição que Jânio Quadros (UDN) consagrar-se-ia presidente. Isto também pode ser observado quando se analisa a linha dominante de suas programaçôes: música popular brasileira (Agostinho do Santos, João Gilberto, Dorival Caymi, Juca Chaves) e festival do Cinema Brasileiro (OrTIZ, 1988, p.50).

Interessante notar como este processo influenciou o lazer, primeiramente ocorre a urbanização e, consequentemente, aumentam as possibilidades de práticas de lazer; posteriormente o próprio lazer se multiplica constituindo lazeres; em seguida a mesma urbanização permite sua crítica utilizando-se de toda tecnologia industrial, transformando o lazer em múltiplas tendências e formas de interpretar a sociedade, como os diferentes filmes, peças, músicas, livros, programas de rádio e televisão. A forma lazer, portanto, acompanha a discussão habermasiana de desenvolvimento do Mundo da Vida, criação de subsistemas e surgimento dos Sistemas Dinheiro e Poder.

O Mundo da Vida, representado pelos sujeitos sociais, ao sentir-se suprimido pelo Sistema, cria formas alternativas de lazer por meio da própria tecnologia, para dirimir a força do Sistema. Surgem as críticas ao lazer de Mercado e da Indústria Cultural, caso do Cinema Novo que critica os filmes norte-americanos, do teatro que critica a falta da cultura popular nas peças, da música que incorpora o regionalismo e da literatura que descreve a história do povo. A crítica fortalece o grupo reproduzindo o Mundo da Vida.

\section{Lazer e Ditadura: os avanços e retrocessos no tempo livre ${ }^{1}$}

\section{A censura, a repressão, a produção artística e o lazer}

Foi uma dura derrota para a intelectualidade de esquerda o golpe de 1964, o sonho de construção e transformação eram grandes, mesmo aqueles que não eram de esquerda, mas acreditavam na democracia, sentiram a crise política.

Pós-AI-5 todos os artistas sentiram a influência restritiva de direitos e liberdade por parte dos militares. Porém houve uma restrita, mas barulhenta, manifestação artística.

O regime militar, segundo Borges (1983), foi considerado o auge do cinema brasileiro, depois houve a queda do financiamento com a decadência do milagre brasileiro e posterior redemocratização.

A maioria dos filmes, segundo OrTIZ (1988), tem no urbano sua referência. Retratos de uma classe média decadente com Arnaldo Jabor; ou mesmo situações singulares com "Dona Flor e seus dois maridos". Distintos dos filmes das Companhias
Atlântida ou Vera Cruz, que anteriormente retratavam historicamente o Brasil, com seus heróis caipiras, ou suas musas tropicais, o cinema brasileiro agora vai expressar os problemas urbanos, a decadência da família e dos valores cristãos. Mostra, também, a miséria do nordeste e as favelas do Rio ou descrevendo a vida dos marginalizados como o filme "Pixote".

Grande parte dos filmes foram censurados totalmente ou sofreram cortes na sua edição. Os militares tinham como discurso que não deveriam apresentar o Brasil como país da desigualdade, e sim como país do futuro, do investimento e das oportunidades. Outros filmes foram censurados por serem pornográficos ou com linguajar obsceno. Para os militares era sua função educar, higienizar corporal e espiritualmente a população. Como era de se esperar os filmes que debatiam os problemas brasileiros, mostrando a fragilidade do milagre econômico bem como das políticas sociais, também foram censurados.

As colocações anteriores reforçam a tese que houve um refluxo nas práticas de lazer durante o 
regime militar. A impossibilidade de encontros sociais nas ruas, censurar as poesias e os filmes mostram que houve um direcionamento político nas práticas de lazer. O governo ao decidir o que seria assistido e como seria estava influindo literalmente nas opções de lazer dos brasileiros, demonstrando claramente que o tempo livre e seu uso foi uma arma amplamente utilizada pelo regime para manter a população longe dos ideais democráticos (AlmeIDA \& Gutierrez, 2005).

Utilizando o olhar habermasiano, pode-se afirmar que com a ampliação do poder do Estado por meio dos atos institucionais, ele se sobrepõe às outras esferas que compõe as sociedades complexas, como o Sistema Dinheiro e o Mundo da Vida. Como apresentado no item metodológico o Sistema Dinheiro é um dinamizador das práticas de lazer. Já o Mundo da Vida é o armazém do saber humano e onde ocorrem as práticas espontâneas de lazer. Quando o Sistema Poder, representado pelo Estado, invade o Sistema Dinheiro diminuindo o número de práticas de lazer devido a censura, há repressão e direcionamento das atividades, como ocorreu com o cinema, poesia, música e teatro, ocorre uma subtração das atividades de lazer. Quando a influência do Estado cresce e se sobrepōe ao Mundo da Vida ocorre um empobrecimento das atividades de lazer. Isso ocorre principalmente quando o Estado reprime os encontros pelo decreto de estado de sítio, por exemplo, o que para Habermas seria uma supressão das relações intersubjetivas.

O Departamento de Censura e Diversões Públicas da Polícia Federal, até 1988 censurou cerca de 25 mil filmes (nacionais e estrangeiros). Fica mais que claro a importância do lazer como meio de controle dos militares. Para eles os filmes faziam parte da diversão pública. A ideia de manter coeso o espírito do milagre econômico, a falsa ideia de um país democrático e, principalmente, manter os valores morais e da família brasileira foram os argumentos utilizados pelos militares para justificar as intervenções nas práticas de lazer.

\section{A produção artística nacional-popular e a censura}

Para intervir na produção cultural os militares criaram órgãos específicos que atuavam no momento de lazer da população. Dos filmes às atividades físicas os militares faziam-se presentes, ou para construir uma identidade nacional ou destruir as formas de resistência.

Apesar do rádio ter sido rapidamente controlado pelo Sistema Nacional de Informação existiram fatos inusitados durante o regime de exceção que cabe uma rápida passagem. Ridenti (1999) lembra da transmissão ao vivo da música de Geraldo Vandré "Para não dizer que não falei das flores" ou "Caminhando", claramente com ímpetos revolucionários, nos festivais.

A música, para Ridenti (1999), Hollanda (1980), Ortiz (1988) e Favaretto (2000), foi um instrumento de contestação política como a tropicália de Gilberto Gil e Caetano Veloso ou os sambas de protesto de Chico Buarque como "Você" e "Cálice". Muitos dos músicos foram reprimidos pelo DOICODI como Geraldo Vandré, outros foram exilados, como Chico Buarque, Gilberto Gil e Caetano Veloso.

Com o milagre econômico o rádio perderia espaço para a televisão, ocorrendo um fato interessante, os dois meios de comunicação mais importantes do Brasil tiveram seu desenvolvimento nos regimes ditatoriais, o rádio com o Estado Novo e a televisão com o Regime militar. Coincidências à parte, estes fatos reforçam a tese de ARENDT (1989).

Outro aspecto importante sobre o refluxo das práticas de lazer é a perda do espaço coletivo para encontros das pessoas. A rua como local de lazer já havia cedido espaço devido a urbanização, a exploração imobiliária e o aumento da frota de veículos. Mas a repressão acelerou este processo e substituiu o encontro na rua pela televisão e cinema. É interessante notar que atividades de lazer como o cinema e televisão casam-se perfeitamente com a repressão nas ruas, pois a censura do Serviço Nacional de Informação nas peças, músicas, filmes, programas de rádio e tv dão a segurança ao governo que a população não se envolva com temas subversivos (Almeida \& Gutierrez, 2005).

\section{A música, o teatro, o cinema e as atividades físicas: lazeres conectados ao regime}

Para aliviar as tensões sociais, decorrentes dos acontecimentos narrados no item anterior, os militares investiram na propaganda política: "Brasil ame-o ou deixe-o", por meio de sistemas tecnológicos modernos, incorporados no cotidiano com incentivo do Estado, formando todo um aparato ideológico baseado nas artes audiovisuais (RAMOS, 1983, p.32). Com a censura muita bem desenvolvida em todos os outros ramos comunicativos como o rádio, cinema, livros, textos e músicas; a televisão, que teve seu auge no período, foi utilizada pelo sistema para formar uma ideologia governista de harmonia, desenvolvimento econômico e social, apoio aos militares e diversão. Com a televisão temos o Estado compactuando com a indústria cultural, 
com investimento em temas como as telenovelas, os programas humorísticos e o esporte (ORTIZ, 1988).

Para compreender estes fatos é necessário reportarse ao "Milagre Econômico". Este se deu em todas as áreas: financeira, urbana, agroindústria, televisivas, recreativas e institucionais; com os tão famosos empréstimos a corrida desenvolvimentista com capital externo que levou o Brasil ao papel de potência econômica mundial - oitava economia mundial - com custos sociais, como ser por bastante tempo, líder em concentração de riqueza, ser o país com maior analfabetismo da América do Sul e possuir índices de desenvolvimento humano próximos aos países africanos. Por outro lado, o país viu-se com um aparato tecnológico de primeiro mundo, um grande parque industrial no sudeste, programas de desenvolvimento econômico em todo país, substituição de importação de bens supérfluos, incentivo ao esporte, investimento na segurança nacional e um sistema nacional de informação que faria todo o controle repressivo às contestaçôes ao regime militar (SKIDMORE, 1988).

Durante o período de Médici o lazer desta classe média se pautava por atividades próximas às elites internacionais, como as viagens para outros países; a criação de espaços turísticos e hotéis; os passeios nos fins de semana (já que os militares continuaram a construção das estradas por todo país, que posteriormente seriam diminuídas pela crise do petróleo da década de 70); acesso a filmes que não fossem censurados; a ampliação dos museus; as músicas da indústria cultural; a expansão e criação de clubes. Em resumo, podemos dizer que o lazer da classe média no Brasil, após o desenvolvimento industrial e das cidades, acompanhou, com algumas peculiaridades, como a censura, o desenvolvimento do lazer dos países industrializados. Ao mesmo tempo, os setores de mais baixa renda tiveram seu espaço de lazer, como a rua e as manifestações populares, restringidos. Com pouco dinheiro e frente às crises emergentes na economia mundial o refúgio foi a casa e as telenovelas, que também serviram como propagandas políticas do regime. Estes dois lados do lazer levam-nos a afirmação que o regime militar possibilitou a elitização do lazer, ou ainda uma concepção dual de lazer que foi ampliado na globalização.

Costa (2000, p.20) afirma que o cinema nacional teve um grande avanço no período militar tanto em produção quanto em divulgação. No período de 1974 a 1980, o governo institucionalizou a chamada "lei de obrigatoriedade", que garantia a exibição de filmes nacionais nos cinemas durante determinada quantidade de dias por ano, cuja aplicação foi defendida e fiscalizada em conjunto pela estatal Empresa Brasileira de Filmes e o Conselho Nacional do Cinema que fixavam por resolução o número de dias/ano a serem dedicados ao cinema nacional. A produção de maior alcance foi a pornochanchada, com a temática "pastelão", uma produção artesanal sem preocupação estética que se tornou ótima mercadoria, com um público amplo e "apoio" da censura.

Fica clara, após esta exposição, a importância política, social e econômica das atividades de lazer para o governo. O Estado, no regime militar, ao mesmo tempo em que continua o projeto desenvolvimentista, procura retirar o caráter político contestatório da produção artística e do lazer, investindo na televisão, no cinema, no turismo, nos parques, nos esportes e nas atividades físicas, para formar um aparato ideológico baseado no tempo livre. Entre 1964-1984 ocorreu uma formidável expansão da produção, distribuição e consumo de serviços ligados a atividades de lazer, de acordo com a necessidade de apoio do governo junto à população.

\section{A consolidação da Indústria Cultural no cenário brasileiro}

O mercado introduziu na sua programação a expressão nacional popular - poesia marginal, cinema novo, teatro do oprimido, CPC, UNE-volante, tropicália - e transformou-as, por meio do processo de colonização - num mercado de consumo ligado ao nacionalismo e desenvolvimentismo com propagandas governamentais. $\mathrm{O}$ exemplo clássico deste nacionalismo sem engajamento, juntamente com o afastamento da estética e a desistência de algo inovador foram as novelas. Tornaram-se um investimento seguro e rentável, de retorno garantido, ao mesmo tempo em que a produção cultural com alguma conotação política apresentava-se como um negócio duvidoso, mormente ante o risco de sequer serem liberadas para exibiçóes. Estimulava-se assim a proliferação da indústria novelística, ao passo que se embaraçava a existência de obras voltadas para temas políticos.

A televisão brasileira foi ao ar em 1950 com a TV Tupi em São Paulo, porém, somente no regime militar, com o investimento estatal, ela obteve a abrangência de uma grande emissora de comunicação. Anteriormente restrita a grupos de classes altas que podiam comprar os aparelhos, posteriormente, no milagre econômico, com o incentivo da produção nacional de televisores e das antenas, desenvolveu-se o setor.

A integração nacional que estava entre as prioridades do Estado militarizado, pode ser entendida como um desdobramento lógico do que, na época, 
se chamou doutrina de Segurança Nacional. A ideia dos militares era fazer do Brasil uma grande nação, diminuir as distâncias regionais no âmbito social, econômico e espacial. A construção da transamazônica é parte desta ideologia. Os militares sabiam que os meios de comunicação eram importantes para a formação e coesão social, tanto na ideia de proteção externa, quanto interna. KoRNIS (2000, p.8) descreve a importância da Embratel na estratégia militar.

A televisão transformou, segundo ORTIZ (1988), todas as expressões artísticas com a incorporação tecnológica. Estes são motivos suficientes para demonstrar a força e a importância da televisão como forma de lazer no Brasil. As novelas foram a grande invenção nacional. Capazes de prender mais de $70 \%$ dos telespectadores, com seu linguajar cotidiano, temas da vida privada e diversidade cultural. Segundo KoRNIS (2000, p.111) em 1964, quando a história da televisão brasileira começaria, o Brasil tinha 34 estações de TV e 1,8 milhão de aparelhos receptores. Em 1978, já eram 15 milhões de receptores. Em 1987, 31 milhōes de televisores se espalhavam pelo País, dos quais 12,5 milhões em cores. Hoje, trata-se do sexto maior parque de receptores instalados no mundo.

Um dos grandes momentos da televisão brasileira foi a transmissão da Copa do Mundo de 1970. O Brasil se uniu diante dos monitores vibrando de patriotismo. Tal foi a repercussão desta copa que os militares utilizaram como propaganda política, consagrando alguns slogans que se aliariam ao "Brasil ame-o ou deixe-o", como: "País que dá certo"; "A copa do mundo é nossa, com brasileiro não há quem possa"; ou ainda: "Noventa milhões em ação pra frente Brasil do meu coração, salve a seleção."

Numa feliz constatação de GASPARI (2002a, p.208) "País, Futebol, Copa, Seleção e Governo misturavam-se num grande carnaval de julho". As conquistas do Pan-Americano e as medalhas Olímpicas também serviram como ufanismo brasileiro, mostrando que o programa esportivo desenvolvidos pelos militares e a obrigatoriedade da educação física na escola foram estratégias vencedoras.

Depois de 1980, quando se inicia o processo de redemocratização, segundo RIDENTI (1999), há uma ampliação dos bens culturais industrializados, pois se há o fortalecimento da indústria cultural com os militares é no período de abertura política que ela chega ao seu apogeu. Sem a censura os filmes, livros e programas nacionais e internacionais tiveram a possibilidade de serem divulgados amplamente. Com a abertura política ficou mais fácil a penetração dos bens culturais de massa a serem lançados e consumidos pela população.

A abertura política, no começo da década de 80 , propiciou um desenvolvimento vertiginoso da indústria cultural, em função principalmente dos investimentos que já tinham sido realizados durante o regime militar na área das comunicaçôes, sempre sob controle dos órgãos de censura. Porém, é preciso ter presente que enquanto a expressão típica da indústria cultural no regime militar caracterizou-se pelo nacional desenvolvimentismo, a indústria cultural na redemocratização e nos períodos subsequentes foi marcada pela globalização e pelo fim da censura. Estes dois acontecimentos mostraram ser o casamento perfeito para o desenvolvimento de práticas de lazer típicas dos países do cone sul pós-ditadura.

Com a democratização das relaçóes, o que se percebe não é uma retomada imediata das relações originais do Mundo da Vida, mas um aumento da importância do Sistema Moeda com uma forte mercantilização das práticas de lazer e, particularmente, do esporte num sentido amplo.

\section{As atividades de lazer no mundo Contemporâneo: globalização}

\section{Ações governamentais e as práticas de lazer}

No período pós Médici iniciou-se a liberalização política da sociedade, lenta gradual e segura ( $\mathrm{SI}_{\mathrm{KI}}$ DMORE, 1988). As ações do poder governamental determinaram o ritmo e o alcance das mudanças, como exemplo a Lei Falcão de 1976 e o pacote de abril de 1977, a primeira impedia que os candidatos falassem nos programas televisivos, e a segunda inseria a figura do senador biônico.
No final do governo Figueiredo, depois de 20 anos de autoritarismo, a pressão para ampliar a democratização intensificaram-se, sobretudo com as mobilizações populares a favor das "Diretas Já!" lideradas pelos partidos da oposição (PMDB, PDT, PT e outros) e com apoio de instituições da sociedade civil como a Ordem dos Advogados do Brasil (OAB), a Associação Brasileira de Imprensa (ABI) e a Conferência Nacional dos Bispos do Brasil (CNBB), as manifestações, não impediram a derrota no Congresso em abril de 1984 da emenda 
do deputado Dante de Oliveira do PMDB. GASPARI (2002b) lembra que a votação da emenda das diretas ocorreu sob um clima ameaçador em virtude do estado de emergência decretado em Brasília.

Com a eleição de Tancredo e seu vice pelo colégio eleitoral inicia-se um novo período histórico, denominado de redemocratização. José Sarney foi o nome deste período, juntamente com Ulysses Guimarães. Sarney herdou dos militares uma crise econômica sem precedentes na história brasileira, com hiperinflação, dívida externa galopante e juros altos.

O governo Collor manteve o crescimento negativo e teve uma postura bastante regressiva quanto a atuação do Estado na promoção de cultura. PARENTE (1995) discute os cortes na cultura, como o fechando da Embrafilme, Embratur e o Ministério da Cultura mostrando a política de afastamento do Estado nas ações culturais.

Silva, Frederico e Araújo (2003, p.319) apresentam números que reforçam as colocações sobre a importância do Estado na promoção da cultura. Os números apresentados pelo Concine referem-se a produção cinematográfica, mas podem ser ampliados para toda a produção cultural. Durante o regime militar com o investimento estatal e o milagre econômico o cinema nacional viveu sua época áurea, para ter uma ideia em 1971 foram produzidos 76 filmes, nos anos seguintes a produção manteve-se nesta média. Já em 1977, no começo da abertura, a produção alcançou o recorde de 87 filmes. Deste ano em diante o número de filmes crescia bastante, principalmente pela diminuição da censura e ampliação de temas possíveis de serem explorados, chegando em 1980 a produzir 93 filmes e o grande recorde de produção ocorreu em 1984 com 108 filmes. Com a crise econômica que enfrentou o governo Sarney a produção diminuiu, principalmente pela falta de mercado consumidor, mas manteve-se a média de 80 filmes/ano. No entanto, com a ação do governo Collor de extinguir a Embrafilme e destituir o Ministério da Cultura, o número de filmes em 1990 caiu para sete produções, nem mesmo nos anos de surgimento do cinema com a companhia Atlântida e Cinédia os números foram tão baixos, mas o pior ano da história do cinema seria o de 1992 com somente duas produções. A situação se regularizaria nos primeiros anos do governo Itamar, mas somente com a criação do Concine em 1996 no governo Fernando Henrique Cardoso teremos o chamado "cinema de retomada" com 23 produçôes naquele ano.

Com a consolidação da democracia, ocorre no Brasil o que HabERMAS (1987b) denominou avanço da esfera pública. No período analisado neste texto, do Estado Novo até a Nova República, sempre houve intervencionismos estatais, muitas vezes com a ideia de proteção da população, no entanto, a intervenção do Estado nos espaços públicos minimiza a influência dos grupos locais, que são cooptados pelo governo como ocorreu no governo Vargas e no Regime Militar. Com a participação efetiva dos grupos civis no cenário nacional e com a desconstituição das agências governamentais de controle ocorreram avanços na esfera pública, tendo como função exigir os direitos fundamentais da Constituição e participação no cenário político. Alguns exemplos de atuação popular foram: as Diretas Já, as eleiçōes livres e o "impeachment" de Collor.

\section{Globalização: influência no lazer contemporâneo}

Com a estagnação do capital produtivo e o investimento no consumo, a grande mudança conjuntural do capitalismo será a ampliação vertiginosa das grandes empresas de serviços, superando as de bens de produção no Brasil. Número de empresas de cinema, companhias de teatro, agências de turismo, parques temáticos, estrutura hoteleira em locais paradisíacos, opções de turismo, enfim, o afastamento do Sistema Poder possibilitou o Sistema Dinheiro investir no lazer dinamizando as atividades, acontecendo um processo diverso do regime militar. Com os militares, o Sistema Poder invadiu todas as esferas da sociedade, primeiramente o Mundo da Vida (com a sociedade vigiada) e posteriormente o Sistema Dinheiro (com a proibição de atividades do entretenimento). $\mathrm{Na}$ globalização, diferentemente, quem invade todas as outras esferas da sociedade é o Sistema Dinheiro, primeiramente invade o Sistema Poder, por meio do controle de gastos públicos e privatizações e, posteriormente, o Mundo da Vida, por meio do número de práticas de lazer mercadológicas.

Para o autor alemão é crucial, para a compreensão da globalização, o conceito de esfera civil, ela se expressa na luta dos atores sociais pelos direitos subjetivos constitucionais, garantia da estrutura de autonomia da coletividade e do indivíduo, bem como da diferenciação da sociedade civil em relação ao Estado e à economia (HABERMAS, 1989, p.82-131).

A globalização trouxe importantes êxitos no campo dos direitos humanos, incentivou a gênese de um direito mundial, estimulou a sensibilidade para problemas ecológicos e para o avanço da democratização de sociedades nacionais, criaram-se formas novas de 
discussão, fóruns de debate e questionamento de atitudes antidemocráticas, todas estas açōes foram disseminadas, diferentes grupos constituíram canais de troca de informação que possibilitam pressões nos governos nacionais.

No lazer a ampliação da sociedade civil possibilitaria uma maior interação subjetiva, diversidade de locais de troca de informação e encontro de grupos comunitários. Com a democratização e a globalização a possibilidade de interação é ampliada, influindo no lazer, já que ele surge da necessidade de socialização, divertimento e busca de prazer com seus pares. A possibilidade de encontros em bares e restaurantes; o aumento dos locais para divertimento, como parques temáticos; o crescimento do turismo e de formas alternativas de se viajar; os locais para prática de atividade física que aumentaram significativamente nos últimos anos, como as academias e parques; as escolinhas de esporte como mais uma opção para as crianças; os acampamentos de férias e locais onde os jovens podem ir sem os pais; o uso da Internet como forma de lazer; os jogos eletrônicos; enfim as práticas de lazer têm no período democrático a sua forma mais ampla e irrestrita de atividade.

Portanto, o lazer se expressa tanto comunicativamente quanto estrategicamente. Pode-se afirmar que o lazer nasce no armazém do saber humano que é o Mundo da Vida, e se há uma ampliação de formas de interação e atuação do Mundo da Vida logicamente o lazer comunicativo tende a se ampliar, da mesma forma que o Estado, por meio de políticas públicas ou o Mercado, por meio de atividades lucrativas, também se ampliam.

\section{O lazer e a cultura nacional em tempos de globalização}

Com o processo de incorporação da tecnologia, mídia e informação há uma acelerada transformação em todos os campos culturais e principalmente nas atividades de lazer, como o surgimento da Internet, tv a cabo, música eletrônica, parques temáticos, meios de transporte mais eficientes, turismo, todos estes fatores transformam aquilo que chamamos atividades de lazer.

A globalização e o fim da censura mostraram ser o casamento perfeito para inserção do Brasil no lazer de primeiro mundo, concomitante com a exclusão social e dificuldade de acesso a um lazer pago para a maior parte da população.

O número de televisores no Brasil, por exemplo, cresceu exorbitantemente, de acordo com a pesquisa de Santana e SouZa (2003, p.252), em 1970, começo do milagre econômico, tínhamos 64 televisores para cada mil habitantes, em 1980, reflexo da economia, este número subiu para 124; ocorreu uma pequena desaceleração no período Sarney e Collor com 190 televisores e o Brasil entra na esfera do sexto maior parque de televisores do mundo com Cardoso, atingindo 224 televisores para cada mil habitantes.

Refletindo as discussões sobre a produção cultural e a relação com os acontecimentos na história brasileira, a televisão foi o casamento entre investimento governamental, afastamento do Estado e inserção da Indústria Cultural nos lares brasileiros, tornando-a, televisão, a maior fonte de lazer.

Há uma forte hipótese que a Indústria Cultural no Brasil não seguiu os contornos que Ianni e Ortiz afirmavam, no final da década de 90, sobre a internacionalização da cultura nacional, a partir de leituras de Adorno e Horkeimer, Benjamim e Morin, o Brasil mantém uma forte presença da arte nacional-popular. Segundo Alvarez (2003, p.343-55) 70\% das companhias gravadoras são de cantores nacionais; $80 \%$ das músicas que tocam nas rádios são nacionais; $60 \%$ dos livros comercializados são de autores nacionais; $20 \%$ dos filmes exibidos nas salas de cinema são nacionais. Estes dados apresentam que o discurso da globalização muitas vezes é determinista a ponto de desconsiderar que, no caso brasileiro, existe uma forte presença da cultura e das artes na vida da população.

Desde a quebra de paradigmas na cultura da semana da arte moderna de 1922 houve no Brasil, apesar das diferenças dos governos (Vargas - nacionalismo; Kubitschek - cosmopolitismo antropofágico; Goulart - antropofagia nacionalista; Militares - democracia nacional e ufanismo; Sarney - nacionalismo democrático e FHC - nacionalismo globalizado), existiu a preocupação com a arte nacional.

Exceto no governo Collor que dissolveu diversos órgãos relacionados à produção cultural, tais como: o Ministério da Cultura, a Fundação do Cinema Brasileiro, o Concine e a Embrafilme, todos os outros governos investiram maciçamente na produção cultural, com leis e incentivos para financiamento, como foi colocado durante todo este trabalho.

A "retomada" da produção cultural é mais um exemplo que reforça o papel do governo brasileiro na promoção da cultura. Os incentivos utilizados no cinema, no teatro e nos museus aumentaram de $21 \%$, em 1995, para 60\%, em 1996. Segundo dados levantados de Silva, Frederico e Araújo (2003, p.76).

Nas outras esferas da cultura e das atividades de lazer, tivemos amplo desenvolvimento da indústria 
fonográfica e da vinculação televisiva. A década de 90 será marcada pelo vertiginoso crescimento dos grupos de música popular. No caso da televisão ocorre a multiplicação de programas sensacionalistas de auditório no "horário nobre" (onde antes havia o predomínio das telenovelas e dos grandes telejornais). Com o acesso à tecnologia surge também na produção cultural uma retomada da produção independente.

\section{Análises e possibilidades das atividades de lazer contemporâneas}

Desde a época de Walter Benjamin muita história moderna se passou, de modo que o que ele estudou como reprodutibilidade técnica ganhou um novo sentido neste mundo contemporâneo. Trata-se, mais uma vez, da diferença entre os meios técnicos da produção artística e do conteúdo do produto cultural em si. Benjamin descreveu a reprodutibilidade como um recurso de produção material da arte moderna - inserida num mercado de cultura de massa -, o que destituiria a obra de arte de sua aura: a originalidade. $\mathrm{O}$ que não impediu que os movimentos e vanguardas modernistas tivessem como orientação justamente a originalidade temática ou estética de sua produção artística. Nossa nova forma de interagir com a tecnologia destituiu de sentido a aura benjaminiana, apenas os críticos de arte que frequentam os museus podem dizer da reprodutibilidade técnica, a arte que nasce na era da globalização não somente vive de reproduzir o passado, e sim de inovações e interações com a tecnologia.

Será que viveremos em um mundo onde cientistas desenvolverão experiências com a utilização de sensores para reproduzir integralmente vivências humanas? Colocam-se óculos tridimensionais, vestem-se luvas sensíveis e roupas especiais, cheias desses sensores. Sem sair do lugar, correndo numa esteira rolante, o indivíduo experimenta sensaçôes como escapar de um tiroteio, jogar futebol ou fazer sexo. Esta poderá ser a grande tendência do lazer? A busca por emoçôes virtuais, sem sair de casa fechado no mundo hedonista micro-estruturado? A busca do prazer se dará mais rapidamente com a possibilidade de sensaçóes e simulaçōes bem próximas ou idênticas à realidade?

A bem da verdade os parques temáticos, os cinemas interativos em $3 \mathrm{D}$ e os brinquedos virtuais já exploram este ramo.

A Internet representa uma importante inovação em relação à televisão pelo fato de permitir uma proliferação de produtores de mensagens. Enquanto os fatores da produção televisiva se agregam em um complexo financeiro e infra-estrutural que praticamente determina a natureza oligopolista da exploração econômica do meio, os fatores da produção de sites na Internet são infinitamente mais baratos e menos complexos, permitindo, portanto, uma ampliação estrondosa da capacidade de produção de mensagens na forma de sites por parte de indivíduos e pequenas corporações.

Diferentemente dos meios de comunicação de massa no Brasil que foram consolidados em regimes ditatoriais, a Internet nasceu na democracia, tendo grande circulação e importância cada vez maior no mundo atual. Primeiramente pela velocidade e segundo pela quantidade de informaçôes. O governo consegue minimamente controlar os outros meios de comunicação, mas a Internet pela facilidade de produção de sites acaba ampliando as interpretações das mensagens. Ela pode tanto esclarecer um assunto quanto gerar crise pela velocidade das mensagens veiculadas.

$\mathrm{Na}$ televisão os diferentes tipos de "reality show" reforçam a ideia deste mundo hedonista com a vontade única de ser reconhecido. É o mundo de imagens que coloca David Harvey, os indivíduos buscam ampliar sua imagem e criar um mundo fantástico incoerente com a realidade, apenas as imagens, naquilo que "tudo que é sólido desmancha no ar".

\section{Considerações finais}

O lazer no Brasil desenvolveu-se conforme a complexificação sistêmica da sociedade, vinculado ao cotidiano das pessoas, por meio das manifestações espontâneas, relação entre sujeitos e agir comunicativo. Com o avanço dos sub-sistemas dinheiro e poder, o lazer aparece também de forma colonizada, como nas políticas públicas, nas ações privadas, na indústria cultural ou no uso das comunicações de massa.
O lazer se complexificou a partir da racionalização das formas de vida, sistematização dos tempos e desencantamento do mundo, criando novas maneiras de se manifestar na sociedade. Sua dinâmica histórica acompanhou os eventos políticos, sociais e econômicos, que refletiram nas estruturas que o identificam, como o prazer, a sociabilidade e a diversão. 
Discutimos como se deu este processo de transformação do lazer por meio do desenvolvimento urbano (possibilidade de ampliação de atividades de lazer, como o teatro, o turismo, o cinema); da racionalização da cultura popular pela proibição de certos jogos e brincadeiras (suspensão da briga de galo e das festas juninas); do desencantamento do mundo (sistematização de festas católicas perdendo o caráter religioso); da normatização da sociedade com o Estado criando leis para as práticas de lazer (o Departamento de Imprensa e Propaganda); da influência do Sistema Poder por meio de políticas públicas (Cine-Jornal, Embrafilmes, Embratur e lei Rouanet); das luta dos trabalhadores (a conquista das férias remuneradas e da jornada de trabalho de 40 horas semanais); do desenvolvimento do Sistema Dinheiro ampliando as opções de lazer (estações de rádio, canais de televisão, turismo, esporte de aventura, Internet, parques temáticos). Todas estas colocações reforçam a complexificação sistêmica do lazer que acompanhou, pese suas particularidades, o desenvolvimento da sociedade brasileira.

Outro ponto que deve ser recordado nestas colocações finais refere-se ao uso da metodologia habermasiana de análise, que permitiu unir três grandes tendências do lazer: a que discute o lazer pelos aspectos simbólicos, culturais e sociais; a preocupada com a função estatal, o seu afastamento e as políticas públicas; e a última que defende ou critica, a função do Mercado e da Indústria Cultural como dinamizador das atividades de lazer. A teoria habermasiana faz a síntese entre estas esferas de influência do lazer, colocando os Sistemas e o Mundo da Vida como as formas que a sociedade contemporânea se expressa. Neste sentido é possível analisar o lazer por três pontos de vista sem excluí-los ou colocá-los em graus de prioridade. Os estudos do Mundo da Vida privilegiariam a primeira tendência, o Sistema Poder a segunda e o Sistema Dinheiro a terceira.

Este artigo teve também como função apresentar um cenário geral do desenvolvimento do lazer desde o nacional-desenvolvimentismo com Getulio Vargas, Juscelino Kubitschek, Regime Militar até a globalização com a redemocratização e ampliação vertiginosa do lazer de consumo. Este panorama geral possibilita afirmar que o lazer desenvolveu-se principalmente pelo investimento estatal. No caso brasileiro o Estado investiu em tecnologia (antenas de rádio; câmeras, fitas e estúdios de cinema; satélites para a televisão; cabos, redes, provedores para a Internet), para depois haver exploração com capital privado. Não é demais afirmar que o Estado foi o grande mecenas do lazer brasileiro.

Para concluir este trabalho podemos afirmar que o lazer é fruto das relações entre subjetividades intactas no sistema capitalista, que se desenvolveu por meio da complexificação da sociedade, possuindo uma íntima ligação cultural-artística. Expressando as três esferas do Mundo da Vida (cultura, sociedade e personalidade), por meio do querer do indivíduo, do prazer que está buscando, do local social, da relação intersubjetiva e da ação considerada pelo grupo como lazer, de acordo com os costumes do lugar. O lazer, ainda, reforça a ideia do desenvolvimento social, de classe e poder econômico. Suas expressões palpáveis na sociedade são: atividades sociais em grupos; as práticas populares de lazer (rua, folclore e festas típicas); os teatros; os cinemas; as artes; as atividades físicas; o esporte; a comunicação de massas; as atividades da indústria do lazer.

\begin{abstract}
Analysis of urban development practices related to leisure and cultural production from the nationaldevelopmentalist period to globalization

A general view of the development of leisure will be presented from the national development with Getúlio Vargas, Juscelino Kubitschek and also the military regime until the democratization and globalization period with the large expansion of leisure consumption. This overview will enable to conclude that leisure was developed by the state investment. It was discussed each of the historical moments contemplating the more significant political economic and cultural actions, based on literature review. The objective on this work was to build the systemic complexification of leisure in Brazil, concluding that leisure has been further complicated from the rationalization of life forms, the organization of time and also the world disenchantment. With Habermas's theory was made the synthesis between the spheres of influence of leisure (State, Market and Cultural Organization). In the conclusion, it has presented the
\end{abstract}


definition of leisure as a result of the relationship between subjectivity intact in the capitalist system that has evolved through the complexity of society and its cultural and artistic intimate connection. Expressing the three spheres of the Life World (culture, society and personality).

UnITERMS: Leisure; Culture; History.

\section{Nota}

1. As discussões históricas deste período foram retratadas longamente na tese de doutorado que deu base para este artigo (Almeida, 2008), por motivos de política editorial este item focará apenas as discussões fundamentais, perdendo em amplitude, mas ganhando em objetividade.

\section{Referências}

ALMEIDA, M. Análise do desenvolvimento das práticas urbanas de lazer relacionadas a produção cultural no período nacional-desenvolvimentista à globalização através da “Teoria da Ação Comunicativa”. 2008. Tese (Doutorado) - Universidade Estadual de Campinas, Campinas, 2008.

ALMEIDA, M.; GUTIERREZ, G. O afastamento do nacional popular e a incorporação da indústria cultural no lazer brasileiro: influência do regime militar. Licere, Belo Horizonte, v.8, n.2, p.90-8, 2005.

ALVAREZ, G. Políticas culturais, mercado e espaço público regional. Brasília: Instituto Brasileiro de Relações Internacionais/UNB, 2003.

ARENDT, H. As origens do totalitarismo. Tradução de Roberto Raposo. São Paulo: Companhia das Letras, 1989.

AVANCINI, M.M.P. Nas tramas da fama: as estrelas do rádio em sua época áurea, Brasil, anos 40 e 50. 1996. Dissertação (Mestrado) - Unicamp, Campinas, 1996.

BERNARDET, J. Cineastas e imagens do povo. São Paulo: Brasiliense, 1985.

BORGES, L. 1960-1980, o cinema à margem. Campinas: Papirus, 1983.

CAPELATO, M. Propaganda política e controle dos meios de comunicação. In: PANDOLFI, D. (Org.). Repensando o Estado Novo. Rio de Janeiro: FGV, 1999.

CATANI, A. A sombra da outra: a cinematográfica Maristela e o cinema industrial paulista nos anos 50. São Paulo: Panorama, 2002.

CORBIN, A. L’Avènement des Loisir. In: CORBIN, A. (Org.) L'avènement des loisir (1850-1960). Paris: Aubier, 1995. COSTA, H. Em busca da memória: organização no local de trabalho, partido e sindicato em São Paulo. São Paulo: Página Aberta, 1995.

COSTA, L. Cinema brasileiro (anos 60-70). Rio de Janeiro: 7 Letras, 2000.

FAVARETTO, C. Tropicália alegoria alegria. 3. ed. São Paulo: Ateliê, 2000.

GALVÃO, M.R.E. Cinema: as idéias de "nacional" e "popular". São Paulo: Brasiliense, 1983.

GASPARI, H. A ditadura envergonhada. São Paulo: Companhia das Letras, 2002a.

A ditadura escancarada. São Paulo: Companhia das Letras, 2002b.

GOULART, S. Sob a verdade oficial: ideologia, propaganda e censura no Estado Novo. São Paulo: Marco Zero/CNPQ, 1990. HABERMAS, J. Teoria de la acion comunicativa. Tradução de Manoel Jemenez Redondo. Madri: Taurus, 1987a. Tomo I. . Tradução de Manoel Jemenez Redondo. Madri: Taurus, 1987b. Tomo II.

Consciência moral e agir comunicativo. Tradução de Guido A. de Almeida. Rio de Janeiro: Tempo Brasileiro, 1989. HOLLANDA, H.B. Impressóes de viagem CPC, vanguarda e desbunde: 1960/1970. São Paulo: Brasiliense 1980. KORNIS, M. Agosto e agostos: a história na mídia. In: GOMES, A. Vargas e a crise dos anos 50. Rio de Janeiro: Relume/Dumará, 1994.

. Uma história do Brasil recente nas minisséries da Rede Globo. 2000. Tese (Doutorado) - Universidade de São Paulo, São Paulo, 2000.

ORTIZ, R.; BORELLI, S.; RAMOS, J. Telenovela: história e produção. São Paulo: Brasiliense, 1988. 
PARENTE, A. Cinema brasileiro: anos 80. Comunicação e Política, São Paulo, n.1, v.4, p.29-44, 1995.

RAMOS, J. Cinema, Estado e lutas culturais: anos 50, 60, 70. Rio de janeiro: Paz e Terra, 1983.

RIDENTI, M. Em busca do povo brasileiro: romantismo revolucionário de artistas e intelectuais (pós-1960). Tese (Livre Docência) - Universidade Estadual de Campinas, Campinas, 1999.

SANTANA, S.; SOUZA, N. Indústrias culturais: geração de trabalho e emprego. Brasília: Instituto Brasileiro de Relações Internacionais/UNB, 2003.

SANTOS, A.P. A estética estadonovista. Dissertação (Mestrado) - Universidade Estadual de Campinas, Campinas, 2004. SILVA, A.; FREDERICO P.; ARAUJO, H. O mercado formal de cultura: características e evolução. Brasília: Instituto Brasileiro de Relações Internacionais/UNB, 2003.

SKIDMORE, T.E. Brasil: de Getúlio Vargas a Castelo Branco (1930-1964). Rio de Janeiro: Paz e Terra, 1975. Brasil: de Costa e Silva a Nova República (1964-1984). Rio de Janeiro: Paz e Terra, 1988.

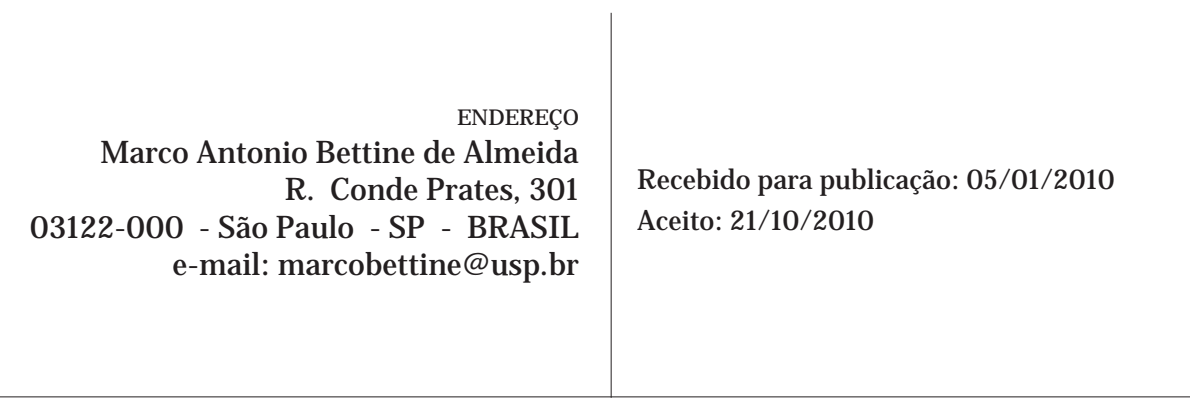

152 • Rev. bras. Educ. Fís. Esporte, São Paulo, v.25, n.1, p.137-52, jan./mar. 2011 